\title{
NGT1 Is Essential for $N$-Acetylglucosamine-Mediated Filamentous Growth Inhibition and HXK1 Functions as a Positive Regulator of Filamentous Growth in Candida tropicalis
}

\author{
Qiuyu Zhang, Li Xu, Sheng Yuan, Qinghua Zhou, Xuxia Wang, Lei Wang, Zhiming Hu and \\ Yunjun Yan *(1) \\ Key Laboratory of Molecular Biophysics, the Ministry of Education, College of Life Science and Technology, \\ Huazhong University of Science and Technology, Wuhan 430074, China; zhangqiuyu@hust.edu.cn (Q.Z.); \\ xuli@mail.hust.edu.cn (L.X.); m201871755@hust.edu.cn (S.Y.); qinghuazhou@hust.edu.cn (Q.Z.); \\ 2017506005@hust.edu.cn (X.W.); 2017511004@hust.edu.cn (L.W.); D201577414@hust.edu.cn (Z.H.) \\ * Correspondence: yanyunjun@hust.edu.cn; Tel.: +86-27-87792213
}

Received: 24 April 2020; Accepted: 1 June 2020; Published: 5 June 2020

\begin{abstract}
Candida tropicalis is a pathogenic fungus that can cause opportunistic infections in humans. The ability of Candida species to transition between yeast and filamentous growth forms is essential to their ability to undergo environmental adaptation and to maintain virulence. In other fungal species, such as Candida albicans, $\mathrm{N}$-acetylglucosamine (GlcNAc) can induce filamentous growth, whereas it suppresses such growth in C. tropicalis. In the present study, we found that knocking out the GlcNA-specific transporter gene NGT1 was sufficient to enhance $C$. tropicalis filamentous growth on Lee's plus GlcNAc medium. This suggests that GlcNAc uptake into C. tropicalis cells is essential to the disruption of mycelial growth. As such, we further studied how GlcNAc catabolism-related genes were able to influence $C$. tropicalis filamentation. We found that $H X K 1$ overexpression drove filamentous growth on Lee's media containing glucose and GlcNAc, whereas the deletion of the same gene disrupted this filamentous growth. Interestingly, the deletion of the DAC1 or NAG1 genes impaired C. tropicalis growth on Lee's plus GlcNAc plates. Overall, these results indicate that HXK1 can serve as a positive regulator of filamentous growth, with excess GlcNAc-6- $\mathrm{PO}_{4}$ accumulation being toxic to $C$. tropicalis. These findings may highlight novel therapeutic targets worthy of future investigation.
\end{abstract}

Keywords: Candida tropicalis; N-acetylglucosamine; NGT1; HXK1; filamentous growth; cell growth

\section{Introduction}

Candida tropicalis is a fungal pathogen that can cause opportunistic infections in humans [1,2]. Candida can cause both relatively superficial infections of the oral mucosa and extremely severe systemic infections that are, in some cases, fatal [3,4] and damaging to tissues, including the spleen, liver, heart, lungs, kidneys, bone, and ocular mucosa [5-8]. Rising numbers of patients who are immunocompromised due to radiotherapy, chemotherapy, or organ transplantation have led to an increase in the incidence of opportunistic Candida infections $[9,10]$. While C. albicans is the most common cause of such fungal infections, $C$. tropicalis infection rates have been rapidly increasing among immunocompromised individuals, and these infections are associated with higher mortality rates [9-11]. In addition, C. tropicalis is more resistant to antifungal agents, such as fluconazole, when compared with C. albicans, with $15 \%$ of $C$. tropicalis isolates being fluconazole-resistant and 
just 3.8\% C. albicans isolates being fluconazole-resistant $[12,13]$. This suggests that $C$. tropicalis is an emerging pathogen worthy of closer study and medical scrutiny.

One important determinant of fungal infectivity in mammals is the yeast-to-filament transition, as well as the ability of these fungi to adapt to changes in the local environment [14-17]. Many environmental factors, including serum conditions, elevated local $\mathrm{CO}_{2}$ levels, a higher temperature within hosts $\left(37^{\circ} \mathrm{C}\right)$, and $\mathrm{N}$-acetylglucosamine (GlcNAc), can drive C. albicans filamentation [15,18-20]. C. tropicalis is evolutionarily similar to C. albicans [13], both of which belong to the CTG clade. A distinguishing characteristic of the species in this clade is that the CTG codon is translated into serine instead of leucine [21-23]. Changes in environmental conditions can also influence $C$. tropicalis filamentation, with shifts in nutrient levels, temperature, $\mathrm{pH}$, and available carbon sources all driving this transition [24,25]. Yeast and filamentous forms of these Candida species exhibit clear differences in their morphology, with changes in cell and colony shape, and in their ability to grow invasively within the host environment $[3,26]$. The yeast-to-filament transition can facilitate endothelial cell penetration by these fungi and spreading within the bloodstream, often resulting in fatal systemic candidiasis [27].

In most mammals, C. albicans is present as a commensal microbe [28,29], whereas C. tropicalis is found in certain mammals and in mangrove sediments, seawater, beaches, sea sediments, and soils in tropical and subtropical regions [30,31]. As a key component of chitin and of the extracellular matrix of animals, GlcNAc is widely present in the environment and in the mammalian hosts, including in the gastrointestinal tract and in the extracellular matrix environment, where it is present within glycosaminoglycans $[32,33]$. Environmental GlcNAc detection is a key function of many fungal species, given that GlcNAc can be used as both a carbon source [34] and as a signaling molecule that can induce morphological changes [35-37].

GlcNAc can readily drive the filamentation of a range of dimorphic fungi, including Histoplasma capsulatum, C. albicans, Yarrowia lipolytica, and Blastomyces dermatitidis [36-38]. However, in C. tropicalis, GlcNAc strongly inhibits filamentous growth [39]. The Ras1-cAMP signaling pathway and many transcription factors have been shown to be involved in both the GlcNAc-induced filamentous growth of $C$. albicans and the GlcNAc-mediated inhibition of $C$. tropicalis filamentous growth $[39,40]$. However, $C$. tropicalis also expresses the genes needed for mediating GlcNAc transportation and catabolism, as does $C$. albicans [21,39]. There is little research on the filamentous growth regulatory mechanisms of $C$. tropicalis. The role of the GlcNAc-specific transporter gene NGT1, as well as the genes responsible for GlcNAc catabolism in this filamentous growth, are still unclear. The relationship between the ability of GlcNAc to inhibit filamentous growth and its metabolic processing is unclear. In the present study, we therefore sought to assess the roles of both GlcNAc catabolic genes and NGT1 in C. tropicalis. We ultimately found that NGT1 was essential for the ability of GlcNAc to inhibit filamentous growth. We additionally investigated the role of the GlcNAc catabolic genes Glucosamine-6-phosphate deaminase (NAG1), N-acetylglucosamine-6-phosphate deacetylase (DAC1), and GlcNAc kinase gene (HXK1), in regulating C. tropicalis filamentous growth.

\section{Results}

\subsection{NGT1 Deletion Enhances C. tropicalis Filamentous Growth on GlcNAc-Containing Medium}

Previous work has shown that, whereas GlcNAc enhances C. albicans filamentous growth, it has the opposite effect on C. tropicalis [39]. In both of these species, the NGT1 protein is composed of several transmembrane regions [21,41] and is essential for efficient GlcNAc uptake [41]. We therefore sought to assess whether NGT1 is similarly required in order for GlcNAc to suppress the filamentous growth of $C$. tropicalis by plating both WT and $n g t 1 \Delta / \Delta$ cells onto Lee's agar plates containing either GlcNAc or glucose at $25^{\circ} \mathrm{C}$ or $37^{\circ} \mathrm{C}$ for 6 days, after which the morphology of the cells and colonies was assessed. On glucose-containing plates, the filamentous growth of $n g t 1 \Delta / \Delta$, WT, and $n g t 1 \Delta / \Delta+N G T 1 p-N G T 1$ reconstituted strain cells showed no apparent difference at both tested temperatures, while the $n g t 1 \Delta / \Delta$ mutant cells underwent filamentous growth more readily than the WT and $n g t 1 \Delta / \Delta+N G T 1 p-N G T 1$ 
reconstituted strain cells at both tested temperatures on GlcNAc-containing plates (Figure 1). We further analyzed the role of NGT1 in the GlcNAc-mediated inhibition of C. tropicalis filamentous growth by overexpressing NGT1. We found that such overexpression had no obvious impact on filamentous growth on these two different media types (Lee's plus glucose and Lee's plus GlcNAc) at both $25^{\circ} \mathrm{C}$ and $37^{\circ} \mathrm{C}$ (Figure 1).

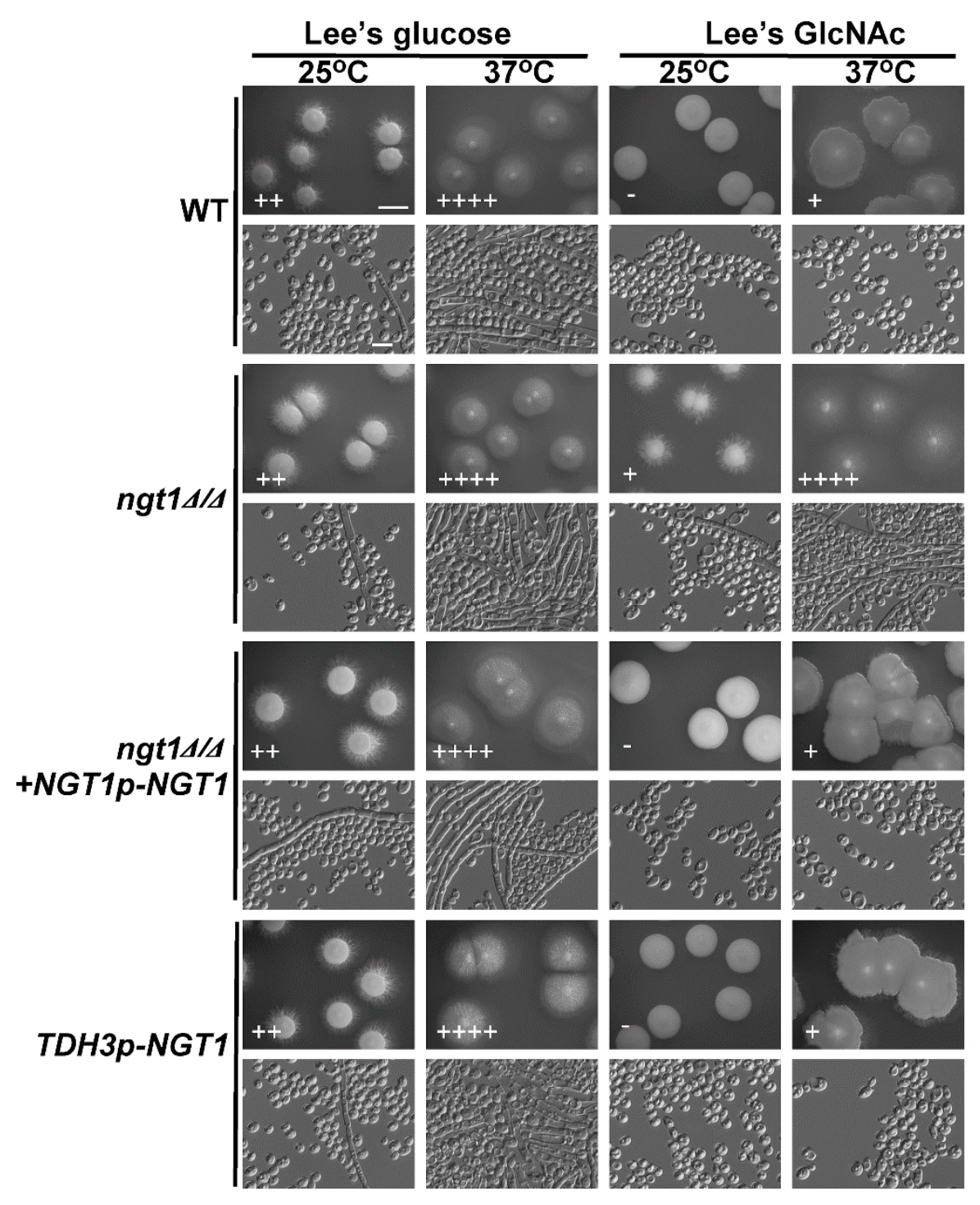

Figure 1. The impact of NGT1 deletion or overexpression on C. tropicalis filamentous growth. WT, $n g t 1 \Delta / \Delta$ mutant, $n g t 1 \Delta / \Delta+N G T 1 p-N G T 1$ reconstituted strain, and NGT1-overexpressing mutant cells were plated on agar plates containing Lee's media containing either glucose or $N$-acetylglucosamine (GlcNAc), and morphology was assessed after 6 days of growth at either $25^{\circ} \mathrm{C}$ or $37^{\circ} \mathrm{C}$. Five individual transformants per gene were used for filamentous growth assays. The degree of hyphal growth is represented by " + " signs, with the percentages of filamentous cells being indicated as follows: ,$+ 0.1 \%-5 \% ;++, 5 \%-20 \% ;+++, 20 \%-40 \%$; ++++, $40 \%-60 \%$. If no hyphal growth was evident, '-' was instead used to indicate cells $(<0.1 \%)$. Scale bars for colonies and cells were $2 \mathrm{~mm}$ and $10 \mu \mathrm{m}$, respectively.

\subsection{GlcNAc Induces HXK1, DAC1, NAG1, and NGT1 Expression in C. tropicalis}

NGT1 encodes a GlcNAc-specific transporter that is required for GlcNAc internalization by C. albicans [41], while HXK1, NAG1, and DAC1 encode GlcNAc kinase, glucosamine-6-phosphate deaminase, and GlcNAc-6-phosphate deacetylase, respectively [21,42,43]. We next assessed how 
the expression of these GlcNAc catabolism-related genes was affected by GlcNAc in C. tropicalis. Using qRT-PCR, it was revealed that the expression of all four assessed genes (HXK1, DAC1, NAG1, and NGT1) was significantly enhanced on GlcNAc-containing media relative to glucose-containing media, with the relative induction of NGT1 being particularly pronounced with a 120-fold increase in its expression (Figure 2). This indicated that GlcNAc was able to readily induce HXK1, DAC1, NAG1, and NGT1 expression in C. tropicalis.

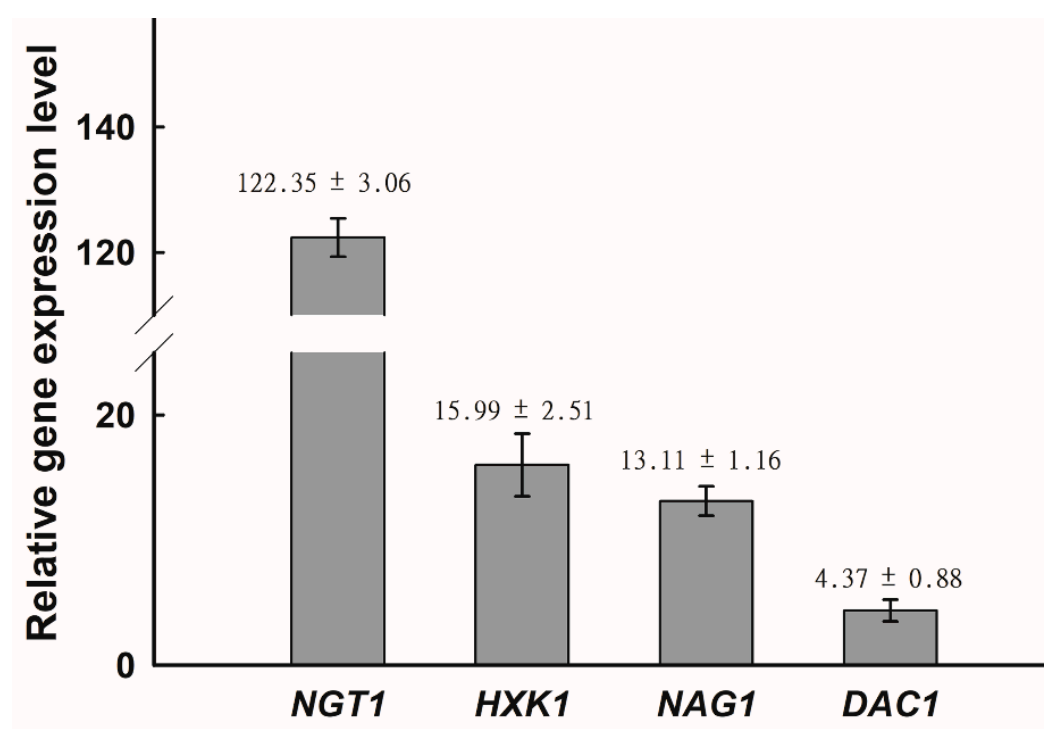

Figure 2. Relative expression of NGT1, HXK1, NAG1, and DAC1 was significantly enhanced on GlcNAc-containing media relative to glucose-containing media. The upregulation of NGT1, HXK1, $N A G 1$, and DAC1 upon growth on Lee's medium with GlcNAc, as compared to Lee's medium with glucose at $25^{\circ} \mathrm{C}$, was assessed via qRT-PCR, with $C$. tropicalis actin (ACT1) being used to normalize gene expression. Gene expression was further normalized, such that expression levels on Lee's glucose agar plates were set to 1 . The average fold change \pm SD is shown above the bar for each gene. Data are means \pm SD from five independent biological replicates.

\subsection{HXK1 Overexpression Promotes C. tropicalis Filamentous Growth}

HXK1, DAC1, and NAG1 are all needed to facilitate the catabolism of GlcNAc. The HXK1 protein phosphorylates GlcNAc, after which DAC1 and NAG1 deacetylate and deaminate it, respectively, yielding fructose-6- $\mathrm{PO}_{4}$ [44]. We next sought to explore the role of these catabolic genes in the filamentous growth of $C$. tropicalis via individually overexpressing each of them under the control of the $\mathrm{C}$. tropicalis $\mathrm{TDH} 3$ promoter. These overexpression mutants were then grown on glucose- or GlcNAc-containing media at $25^{\circ} \mathrm{C}$ and $37^{\circ} \mathrm{C}$. Relative to vector control cells, those cells overexpressing HXK1 exhibited more pronounced filamentous growth on glucose-containing media at $25^{\circ} \mathrm{C}$ as well as on GlcNAc-containing media at both $25^{\circ} \mathrm{C}$ and $37^{\circ} \mathrm{C}$, with the most pronounced effect being evident on GlcNAc-containing media at $25^{\circ} \mathrm{C}$ (Figure 3), as vector control cells exhibited no filamentous growth under these conditions. When grown on glucose-containing Lee's medium at $37^{\circ} \mathrm{C}$, both the WT vector and HXK1-overexpressing strains exhibited robust filamentous growth (Figure 3), thus masking any potential enhancement of filamentous growth under these conditions. These results indicating that overexpression HXK1 promoted filamentous growth in C. tropicalis. In contrast, the overexpression of $D A C 1$ and NAG1 did not clearly impact filamentous growth under any tested conditions (Figure 3). 


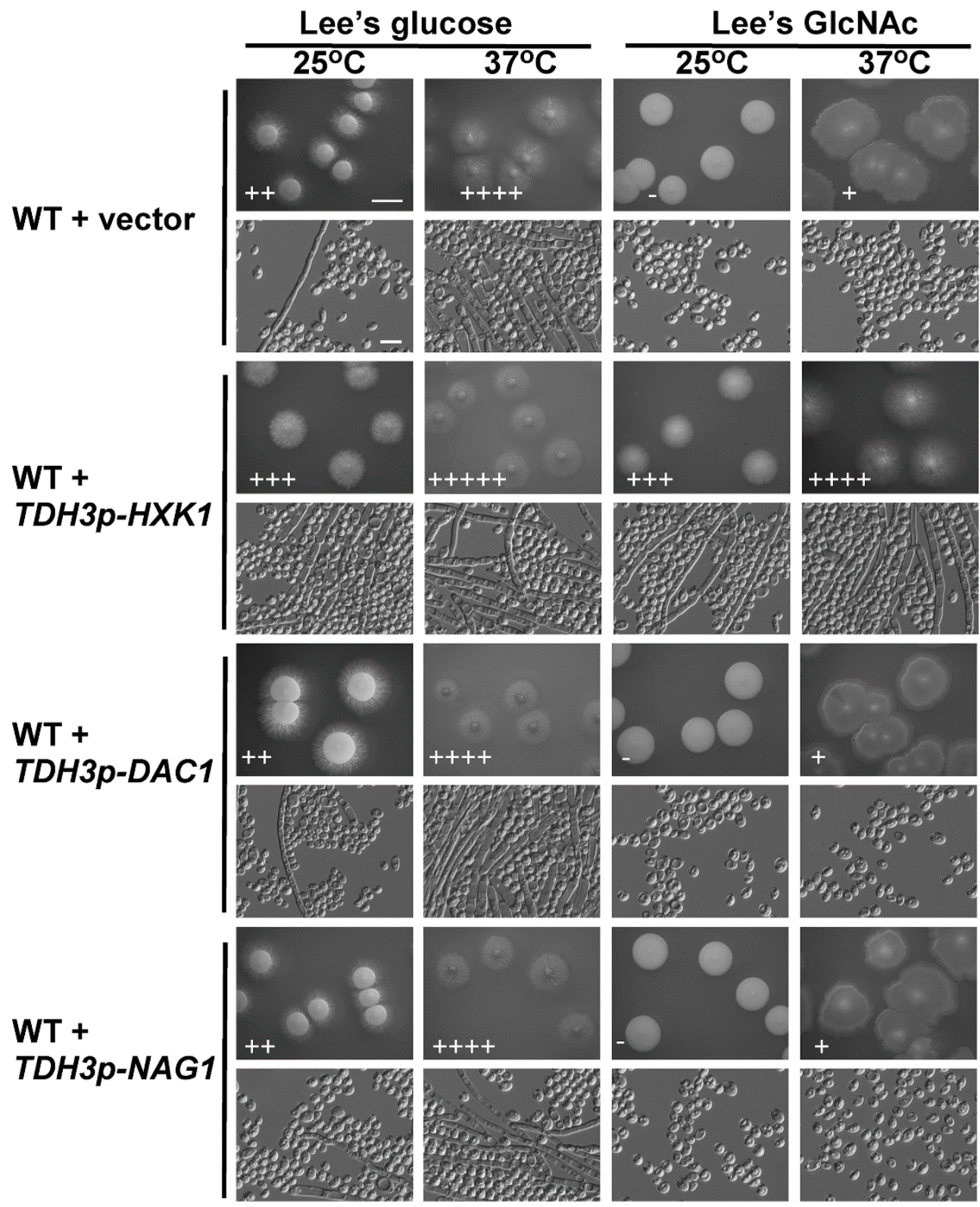

Figure 3. HXK1 overexpression enhanced C. tropicalis filamentous growth. WT or overexpression strains were plated on Lee's agar plates containing glucose or GlcNAc, and cellular/colony morphology was imaged after 6 days of growth at $25^{\circ} \mathrm{C}$ or $37^{\circ} \mathrm{C}$. The WT + vector strain $(\mathrm{GH} 1374+$ pCT3) served as a control. Five individual transformants for each gene were used for filamentous growth assays. The degree of hyphal growth is represented by "+" signs, with the percentages of filamentous cells being indicated as follows:,$+ 0.1 \%-5 \% ;++, 5 \%-20 \% ;+++, 20 \%-40 \% ;++++, 40 \%-60 \% ;+++++,>60 \%$. If no hyphal growth was evident, "-" was instead used to indicate cells $(<0.1 \%)$. Scale bars for colonies and cells were $2 \mathrm{~mm}$ and $10 \mu \mathrm{m}$, respectively.

\subsection{The Impact of HXK1 Deletion on C. tropicalis Filamentous Growth and Cell Growth Rates}

Given that HXK1 overexpression enhanced C. tropicalis filamentous growth (Figure 3), we next explored its importance in this context using HXK1 deletion cells. Consistent with our findings from the overexpression experiments, colonies of $h x k 1 \Delta / \Delta$ mutants were smooth and failed to exhibit filamentous growth on glucose-containing plates at $25^{\circ} \mathrm{C}$ (Figure 4). We similarly observed reduced $h x k 1 \Delta / \Delta$ mutant cell filamentation at $37^{\circ} \mathrm{C}$ on glucose-containing media (Figure 4). This suggests that HXK1 serves to positively regulate filamentation in C. tropicalis, besides its role in GlcNAc catabolism. 
As WT cells exhibited minimal filamentation on GlcNAc-containing plates, the ability of HXK1 deletion to further suppress filamentous growth on these plates was difficult to assess accurately (Figure 4). No clear differences in colony size were exhibited by $h x k 1 \Delta / \Delta$ mutant cells relative to WT cells on glucose-containing plates, but the $h x k 1 \Delta / \Delta$ mutant colonies were markedly smaller than were the WT colonies on GlcNAc-containing plates, indicating that $h x k 1 \Delta / \Delta$ mutant cells grow at a reduced rate on Lee's plus GlcNAc plates.

To confirm that the deletion of HXK1 in C. tropicalis resulted in suppressed filamentous growth and that the cell growth rate was reduced on GlcNAc-containing medium, a fragment containing the HXK1 gene was transformed back into the genome and integrated into the original $H X K 1$ locus. We found that the percentages of filamentous cells and the cell growth rates of the $H X K 1 / H X K 1+H X K 1 p-H X K 1$ complemented strains were similar to those of the WT (Figure 4).

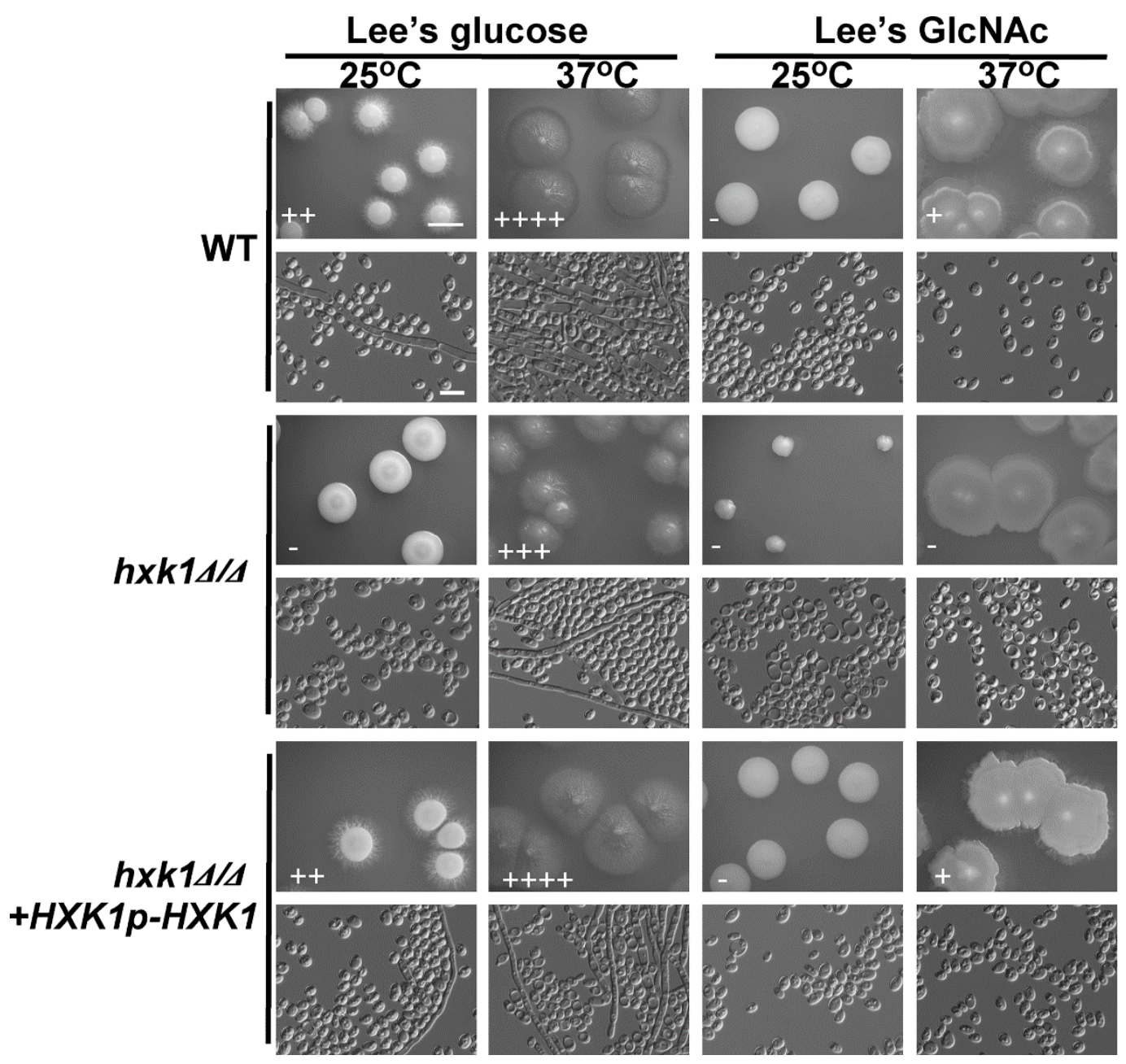

Figure 4. HXK1 deletion markedly reduces C. tropicalis filamentous growth. Cells of WT, $h x k 1 \Delta / \Delta$ mutant, and $h x k 1 \Delta / \Delta+H X K 1 p-H X K 1$ reconstituted strain were plated on Lee's agar plates containing glucose or GlcNAc, and after 6 days at $25^{\circ} \mathrm{C}$ or $37^{\circ} \mathrm{C}$, representative colony and cellular morphology was assessed. Five individual transformants for each gene were used for filamentous growth assays. The degree of hyphal growth is represented by "+" signs, with the percentages of filamentous cells being indicated as follows:,$+ 0.1 \%-5 \% ;++, 5 \%-20 \% ;+++, 20 \%-40 \% ;++++, 40 \%-60 \%$. If no hyphal growth was evident, "--" was instead used to indicate cells $(<0.1 \%)$. Scale bars for colonies and cells were $2 \mathrm{~mm}$ and $10 \mu \mathrm{m}$, respectively. 


\subsection{Assessment of $h x k 1 \Delta / \Delta$ dac1 $\Delta / \Delta$ nag $1 \Delta / \Delta$ Triple Mutant $C$. tropicalis Filamentation and Cell Growth}

HXK1, DAC1, and NAG1 are present within a single cluster of the C. tropicalis genome [21], allowing for the one-step deletion of all three genes. As with the mutant cells lacking HXK1 expression, $h x k 1 \Delta / \Delta$ dac $1 \Delta / \Delta$ nag $1 \Delta / \Delta$ triple deletion mutants were smooth and failed to undergo filamentation on glucose-containing plates at $25^{\circ} \mathrm{C}$ (Figure 5). Relative to WT and reconstituted $h x k 1 \Delta / \Delta$ dac $1 \Delta / \Delta$ nag1 $1 \Delta+H X K 1 p-H X K 1+D A C 1 p-D A C 1+N A G 1 p-N A G 1$ controls, these triple mutant cells exhibited a clear reduction in filamentous growth on glucose-containing medium at $37^{\circ} \mathrm{C}$ (Figure 5). Interestingly, $h x k 1 \Delta / \Delta$ dac $1 \Delta / \Delta$ nag $1 \Delta / \Delta$ triple mutant colonies did not differ obviously in size relative to WT and reconstituted strain $h x k 1 \Delta / \Delta$ dac1 $/ \Delta$ nag $1 \Delta / \Delta+H X K 1 p-H X K 1+D A C 1 p-D A C 1+N A G 1 p-N A G 1$ colonies (Figure 5). In fact, previous research has shown that $C$. tropicalis can grow on Lee's medium without GlcNAc/glucose or other sugars as a carbon source [39]. The robust filamentous growth observed on such media is similar to that observed on Lee's glucose medium, and so we can conclude that the decreased filamentous growth of the triple mutant of $h x k 1 \Delta / \Delta$ dac $1 \Delta / \Delta$ nag $1 \Delta / \Delta$ on Lee's GlcNAc medium is primarily a result of the GlcNAc inhibition of filamentous growth in $C$. tropicalis.

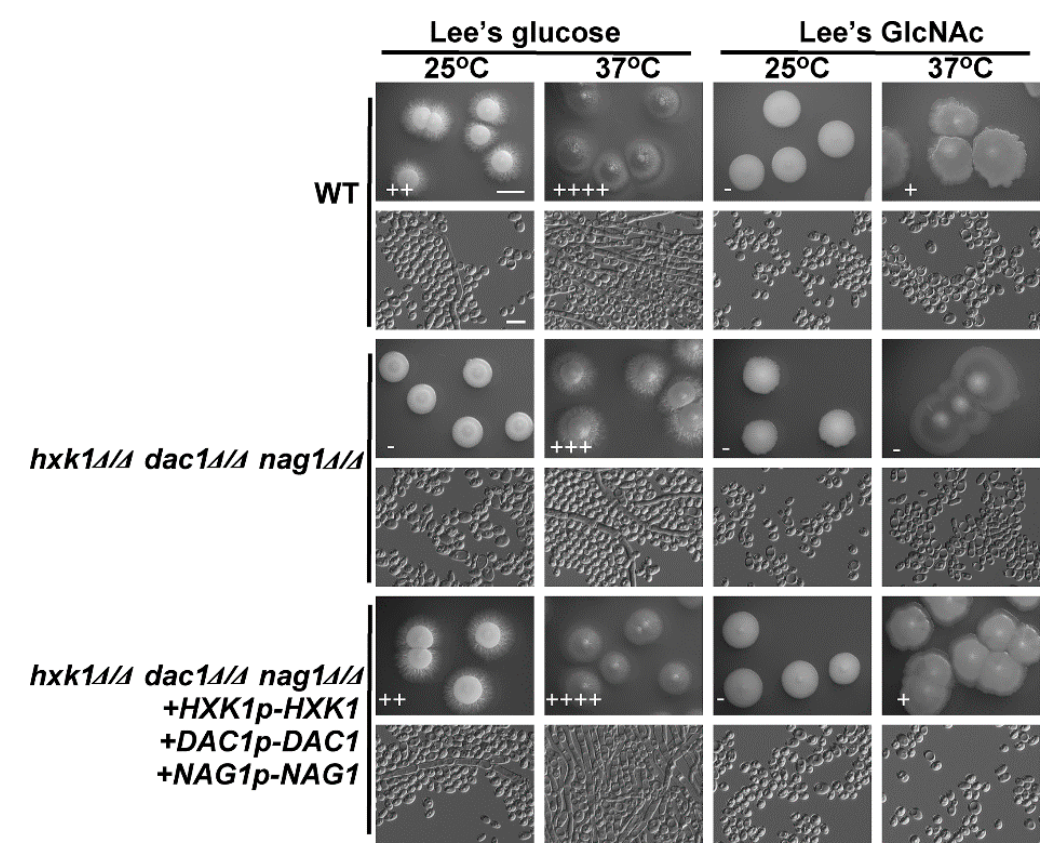

Figure 5. HXK1, DAC1, and NAG1 deletion led to a marked drop in $C$. tropicalis filamentous growth. WT, $h \times k 1 \Delta / \Delta$ dac1 $\Delta / \Delta$ nag $1 \Delta / \Delta$ triple deletion mutant, and $h x k 1 \Delta / \Delta$ dac $1 \Delta / \Delta$ nag1 $1 \Delta+H X K 1 p-H X K 1+D A C 1 p-D A C 1+N A G 1 p-N A G 1$ reconstituted strain cells were plated on Lee's agar plates containing glucose or GlcNAc, and after 6 days at $25^{\circ} \mathrm{C}$ or $37^{\circ} \mathrm{C}$ representative colony and cellular morphology was assessed. Five individual transformants for each gene were used for filamentous growth assays. The degree of hyphal growth is represented by "+" signs, with the percentages of filamentous cells being indicated as follows:,$+ 0.1 \%-5 \% ;++, 5 \%-20 \% ;+++, 20 \%-40 \%$; ,$++++ 40 \%-60 \%$. If no hyphal growth was evident, "-" was instead used to indicate cells $(<0.1 \%)$. Scale bars for colonies and cells were $2 \mathrm{~mm}$ and $10 \mu \mathrm{m}$, respectively.

\subsection{Assessment of the Effects of DAC1 or NAG1 Deletion on C. tropicalis Filamentous Growth}

We next examined the effects of deleting $D A C 1$ or NAG1 on C. tropicalis filamentous growth on glucose- and GlcNAc-containing media at $25^{\circ} \mathrm{C}$ and $37^{\circ} \mathrm{C}$. Notably, both the $d a c 1 \Delta / \Delta$ and nag $1 \Delta / \Delta$ mutants were unable to grow on GlcNAc-containing plates, whereas these cells exhibited normal growth on glucose-containing plates. This suggests that GlcNAc is still able to disrupt $C$. tropicalis growth in these $d a c 1 \Delta / \Delta$ and nag $1 \Delta / \triangle$ mutant cells (Figure 6). Indeed, DAC1 or NAG1 deletion did not clearly impact growth on glucose-containing media at either tested temperature (Figure 6). We were 
unable to test the effects of these deletions on filamentous growth on GlcNAc-containing media, given that GlcNAc inhibited the growth of these mutant cells (Figure 6).

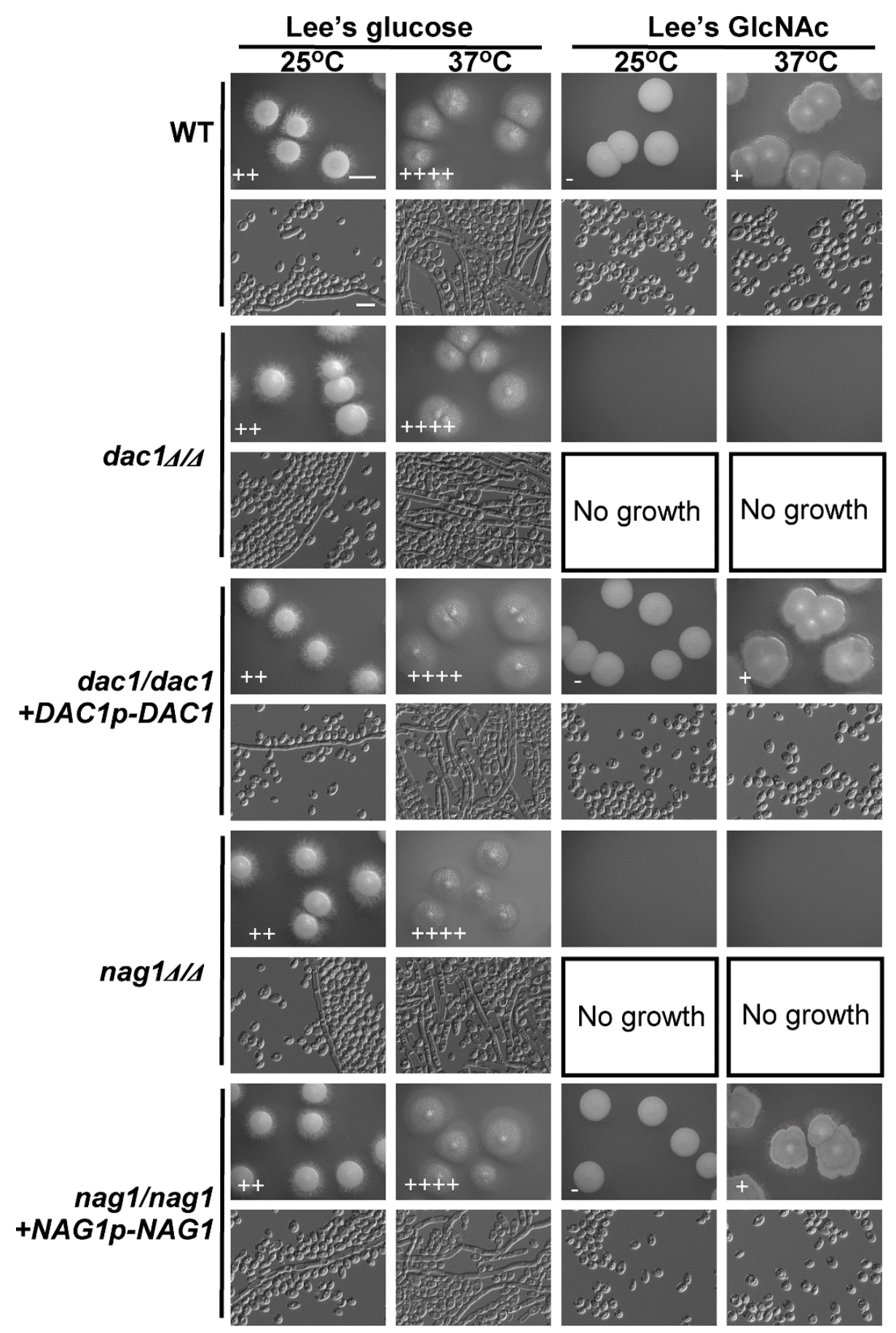

Figure 6. GlcNAc suppresses $d a c 1 \Delta / \Delta$ and nag $1 \Delta / \Delta$ cellular growth. WT, dac $1 \Delta / \Delta$ mutant, dac $1 \Delta / \Delta$ $+D A C 1 p-D A C 1$ reconstituted strain, nag $1 \Delta / \Delta$ mutant, and nag $1 \Delta / \Delta+N A G 1 p-N A G 1$ reconstituted strain cells were plated on Lee's agar plates containing glucose or GlcNAc, and after 6 days at $25^{\circ} \mathrm{C}$ or $37^{\circ} \mathrm{C}$ representative colony and cellular morphology was assessed. Five individual transformants for each gene were used for filamentous growth assays. The degree of hyphal growth is represented by " + " signs, with the percentages of filamentous cells being indicated as follows:,$+ 0.1 \%-5 \% ;++, 5 \%-20 \%$; ,$+++ 20 \%-40 \% ;++++, 40 \%-60 \%$. If no hyphal growth was evident, "--" was instead used to indicate cells $(<0.1 \%)$. Scale bars for colonies and cells were $2 \mathrm{~mm}$ and $10 \mu \mathrm{m}$, respectively. Scale bars for colonies and cells were $2 \mathrm{~mm}$ and $10 \mu \mathrm{m}$, respectively. 
To confirm that the deletion of DAC1 or NAG1 in C. tropicalis inhibited the cells' growth on GlcNAc-containing media, a fragment containing the $D A C 1$ or NAG1gene was transformed back into the genome and integrated into the original $D A C 1$ or $N A G 1$ locus, correspondingly. We found that the cell growth rates of the $d a c 1 \Delta / \triangle+D A C 1 p-D A C 1$ and nag $1 \Delta / \Delta+N A G 1 p-N A G 1$ complemented strains were similar to those of the WT (Figure 6).

\section{Discussion}

The ability to undergo advantageous morphological changes in response to environmental changes is essential to the survival of many microbes. In fungi, the yeast-to-filament transition can facilitate host tissue invasion and spread through the host circulatory system, often leading to the development of fatal systemic candidiasis, making this transition of critical importance for the pathogenicity of Candida species $[45,46]$. While C. albicans and C. tropicalis are closely related fungi, GlcNAc induces opposing outcomes in these species, promoting C. albicans filamentation [20,47], while inhibiting this same transition in $C$. tropicalis [39]. Glucose availability is relatively limited in environments where $C$. tropicalis is normally found, whereas GlcNAc, which is a key component of chitin and of the extracellular matrix of animals, is readily present in diverse environments, including the human gastrointestinal tract $[32,33]$. Candida and other fungal species are able to utilize GlcNAc both as a source of carbon and as a signaling molecule [34,36]. However, previous research has not assessed whether GlcNAc interferes with C. tropicalis filamentation in a manner dependent upon its catabolism. As such, herein we examined how the GlcNAc-mediated suppression of fungal growth is linked to GlcNAc catabolism in C. tropicalis.

NGT1 is a transmembrane protein vital for GlcNAc transport into cells [36,41]. In C. tropicalis cells in which NGT1 had been knocked out, there was no apparent change in fungal growth on glucose-containing plates, whereas on GlcNAc-containing plates, the NGT1 knockout cells exhibited a clear improvement in filamentous growth at $25^{\circ} \mathrm{C}$ and $37^{\circ} \mathrm{C}$ (Figure 1). This thus suggests that GlcNAc entry into $C$. tropicalis cells is required for the subsequent suppression of filamentous growth. Although the deletion of NGT1 resulted in more robust filamentous growth on Lee's plus GlcNAc medium plates, the overexpression of NGT1 had no obvious effect on filamentous growth under any of the four tested culture conditions (Figure 1). These phenomena can be explained by the expression level of the GlcNAc-specific transporter gene NGT1 even in the WT control strain (GH1374), which was efficiently induced when cultured on Lee's plus GlcNAc agar plates (Figure 2), suggesting that this GlcNAc-specific transporter is sufficient to efficiently transport GlcNAc into C. tropicalis cells and to thereby suppress filamentous growth.

Our results revealed that GlcNAc was only able to inhibit $C$. tropicalis filamentation following its NGT1-mediated internalization. Candida species can utilize GlcNAc as a carbon source through a catabolic mechanism dependent upon HXK1, DAC1, and NAG1 [34,43,48]. We found that the expression of NGT1, HXK1, DAC1, and NAG1 were all significantly elevated in cells grown on GlcNAc-containing media relative to those grown on glucose-containing media. Previous work suggests that in C. albicans, HXK1 can suppress filamentation [44]. In C. tropicalis, however, we observed the opposite phenotype, with HXK1 overexpression driving enhanced filamentous growth on both glucose- and GlcNAc-containing media (Figure 3), suggesting that this protein can positively regulate filamentous growth. Consistent with this, HXK1 deletion mutant cells exhibited markedly reduced filamentous growth on glucose-containing media at both $25^{\circ} \mathrm{C}$ and $37^{\circ} \mathrm{C}$ (Figure 4). This suggests that HXK1 is thus able to enhance filamentous growth besides GlcNAc phosphorylation (Figure 7). C. tropicalis may synthesize its own GlcNAc, and the overexpression of HXK1 can eliminate GlcNAc, whereas the deletion of HXK1 cannot eliminate GlcNAc synthesized by C. tropicalis itself, which may repress filamentation. HXK1 is known to physically interact with a histone deacetylase (Sir2), which controls phenotypic switching in C. albicans $[49,50]$. This phenomenon indicates that HXK1 may phosphorylate many substrates in the context of signal transduction [50,51], and as such this positive 
regulatory phenotype may be linked to the enhanced phosphorylation of particular yet-to-be-identified substrates in C. tropicalis.

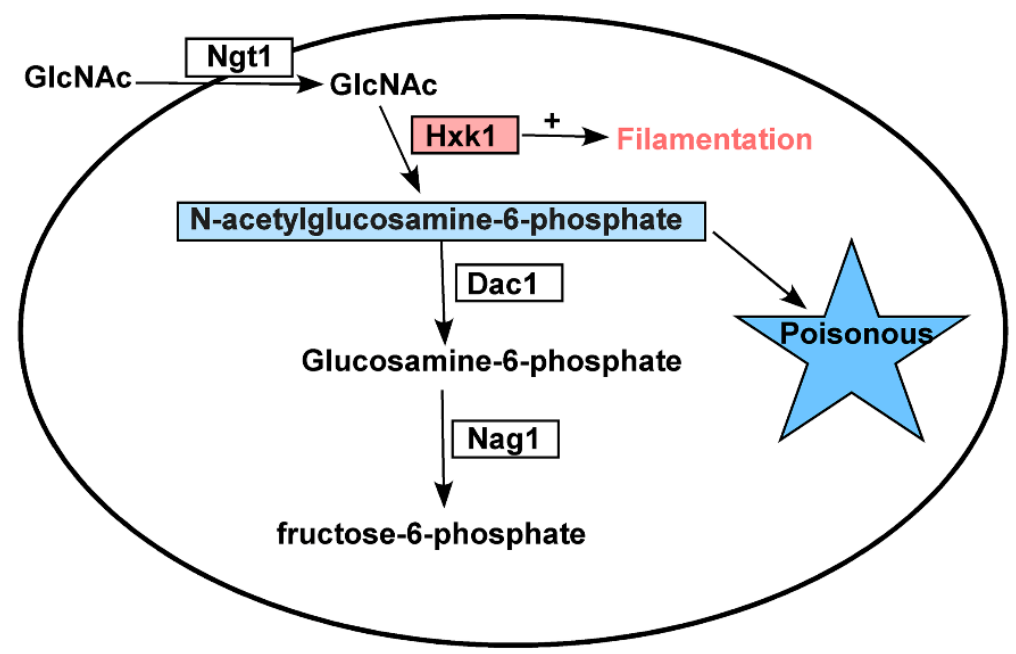

Figure 7. A model of how $N$-acetylglucosamine metabolism-related genes govern C. tropicalis functionality. HXK1 positively regulates filamentous growth in addition to catalyzing the phosphorylation of GlcNAc, with excess GlcNAc-6-PO 4 being toxic to $C$. tropicalis.

Relative to WT cells, we observed a clear reduction in the growth rate of $h x k 1 \Delta / \Delta$ mutant cells on plates containing GlcNAc, which may be a result of the dramatically increased DAC1 and NAG1 expression observed in these cells (Figure 2), leading to the rapid breakdown of GlcNAc-6- $\mathrm{PO}_{4}$, whereas in $H X K 1$ deletion mutants, this GlcNAc-6- $\mathrm{PO}_{4}$ cannot be produced. As such, we generated $h x k 1 / \Delta / \Delta$ dac $1 \Delta / \Delta$ nag $1 \Delta / \Delta$ triple mutant cells and assessed their relative filamentous growth. Compared to WT cells, these triple mutants exhibited no apparent differences in colony size (Figure 5), instead exhibiting filamentous growth similar to that of the $h x k 1 \Delta / \Delta$ mutant under tested conditions, with GlcNAc effectively inhibiting filamentous growth for both $h x k 1 \Delta / \Delta$ and $h x k 1 \Delta / \Delta$ nag $1 \Delta / \Delta$ dac $1 \Delta / \Delta$ mutant cells (Figures 5 and 7). Therefore, these results further supported the ability of GlcNAc to suppress filamentation through a mechanism independent of its catabolic processing.

$D A C 1$ and NAG1 failed to clearly impact filamentous growth under the tested conditions (Figure 6), suggesting that these genes do not play a critical role in the regulation of $C$. tropicalis filamentous growth. This was further supported by the observation that the $h \times k 1 \Delta / \Delta$ dac1 $\Delta / \Delta$ nag $1 \Delta / \Delta$ and $h \times k 1 \Delta / \Delta$ mutant strains exhibited similar filamentous growth under the tested conditions (Figure 5). The $d a c 1 \Delta / \Delta$ and nag $1 \Delta / \Delta$ mutant strains were unable to grow on GlcNAc-containing plates, whereas they grew normally on glucose-containing plates (Figure 6), suggesting that GlcNAc-6- $\mathrm{PO}_{4}$ accumulation induces cytotoxicity in $C$. tropicalis (Figure 7). This is consistent with findings indicating that GlcNAc is able to suppress the growth of $d a c 1 \Delta / \Delta$ and nag $1 \Delta / \Delta$ mutant $C$. albicans strains [44]. This was also consistent with the fact that the $h x k 1 \Delta / \Delta$ dac $1 \Delta / \Delta$ nag $1 \Delta / \Delta$ triple mutant cells grew at a rate similar to WT control cells. Together, these results indicate that $h x k 1 \Delta / \Delta$ cells grow substantially slower on GlcNAc-containing media, suggesting that metabolic balance is essential for normal C. tropicalis cellular growth. 
In summary, these findings indicate that NGT1-mediated GlcNAc transport into C. tropicalis cells is essential in order for GlcNAc to inhibit filamentous growth. Furthermore, HXK1 serves to positively regulate filamentous growth and to phosphorylate GlcNAc. We further found that excessive constitutive GlcNAc-6- $\mathrm{PO}_{4}$ accumulation is toxic to $\mathrm{C}$. tropicalis. Together, these results may highlight potential avenues for future therapeutic intervention.

\section{Materials and Methods}

\subsection{Fungal Culture}

Table 1 details the strains and plasmids used in the present study. C. tropicalis cells were plated or patched onto solid YPD medium (20 g/L glucose, $20 \mathrm{~g} / \mathrm{L}$ peptone, $10 \mathrm{~g} / \mathrm{L}$ Yeast extract, and $20 \mathrm{~g} / \mathrm{L}$ Agar) and were routinely grown at $25{ }^{\circ} \mathrm{C}$. YPM medium $(20 \mathrm{~g} / \mathrm{L}$ maltose, $20 \mathrm{~g} / \mathrm{L}$ peptone, $10 \mathrm{~g} / \mathrm{L}$ yeast extract $)$ was used for the FLP-mediated excision of the caSAT1/flipper cassette [5]. Modified Lee's medium $\left(5 \mathrm{~g} / \mathrm{L} \mathrm{NaCl}, 5 \mathrm{~g} / \mathrm{L}\left(\mathrm{NH}_{4}\right)_{2} \mathrm{SO}_{4}, 2.5 \mathrm{~g} / \mathrm{L} \mathrm{K}_{2} \mathrm{HPO}_{4}, 0.2 \mathrm{~g} / \mathrm{L} \mathrm{MgSO}{ }_{4} .7 \mathrm{H}_{2} \mathrm{O}, 1.3 \mathrm{~g} / \mathrm{L}\right.$ L-leucine, $1 \mathrm{~g} / \mathrm{L}$ L-lysine, $0.5 \mathrm{~g} / \mathrm{L} \mathrm{L}$-alanine, $0.5 \mathrm{~g} / \mathrm{L} \mathrm{L}$-phenylalanine, $0.5 \mathrm{~g} / \mathrm{L}$ L-pronine, $0.5 \mathrm{~g} / \mathrm{L} \mathrm{L}$-threonine, $0.1 \mathrm{~g} / \mathrm{L} \mathrm{L}$-methionine, $70 \mathrm{mg} / \mathrm{L} \mathrm{L}$-ornithine, $70 \mathrm{mg} / \mathrm{L} \mathrm{L}$-arginine, $70 \mathrm{mg} / \mathrm{L} \mathrm{L}$-histidine, $70 \mathrm{mg} / \mathrm{L}$ uridine, $1 \mathrm{mg} / \mathrm{L}$ D-biotin and $\left.16 \mathrm{ug} / \mathrm{L} \mathrm{ZnSO}_{4}\right)$ containing GlcNAc $(12.5 \mathrm{~g} / \mathrm{L})$ or glucose $(12.5 \mathrm{~g} / \mathrm{L})$ was used to analyze filamentous growth [5]. Solid agar plates were prepared by the addition of $20 \mathrm{~g} / \mathrm{L}$ agar (BD, Franklin Lakes, NJ, USA) to Lee's plus glucose and Lee's plus GlcNAc media. The amino acids, inorganic salts, glucose, and GlcNAc used to construct Lee's media were from Sigma-Aldrich (St. Louis, MO, USA).

\subsection{Plasmid Construction}

The $\mathrm{pCT} 3$ vector for $C$. tropicalis was used to generate overexpression plasmids through a slightly modified version of previous protocols [39]. For pCT3-HXK1 overexpression plasmid generation, the ORF of HXK1 along with a 250 bp 3'-UTR region was amplified by PCR using HXK1-specific primers from GH1374 genomic DNA, with NotI and KpnI sites being present within the amplified sequence. NotI and KpnI were then used to digest this sequence, which was inserted into the pCT3 construct downstream of the TDH3 promoter, as TDH3 is the most highly expressed housekeeping gene in C. tropicalis. A previous RNA-Seq analysis found that the mRNA expression level of TDH3 was dozens to hundreds of times that of HXK1, DAC1, NAG1, and NGT1 on both Lee's glucose medium and Lee's GlcNAc medium [39]. The pCT3-NGT1, pCT3-DAC1, and pCT3-NAG1 plasmids were similarly generated through the amplification of NGT1, DAC1, and NAG1 ORFs and $250 \mathrm{bp} 3^{\prime}$-UTR regions from GH1374 genomic DNA using appropriate pairs of PCR primers. NotI and PstI were used to digest the resultant nucleic acids prior to inserting them into the $\mathrm{pCT} 3$ plasmid downstream of the TDH3 promoter. 
Table 1. Strains and plasmids in the present study.

\begin{tabular}{|c|c|c|}
\hline Strain or Plasmid & Description & References \\
\hline \multicolumn{3}{|l|}{ Strains } \\
\hline GH1374 & Natural isolate & [39] \\
\hline TDH3p-NGT1 & GH1374+pCT3-HGC1 & This study \\
\hline TDHЗp-HXK1 & GH1374+pCT3-HXK1 & This study \\
\hline TDH3p-DAC1 & GH1374+pCT3-DAC1 & This study \\
\hline TDH3p-NAG1 & GH1374+pCT3-NAG1 & This study \\
\hline$n g t 1 \Delta / \Delta$ & As GH1374, but $n g t 1: S A T 1 / n g t 1: h p h$ & This study \\
\hline$h \times k 1 \Delta / \Delta$ & As GH1374, but $h x k 1: S A T 1 / h x k 1: h p h$ & This study \\
\hline $\operatorname{dac} 1 \Delta / \Delta$ & As GH1374, but dac1:SAT1/dac1:hph & This study \\
\hline$n a g 1 \Delta / \Delta$ & As GH1374, but nag1:SAT1/nag1:hph & This study \\
\hline$h \times k 1 \Delta / \Delta$ dac $1 \Delta / \Delta$ nag $1 \Delta / \Delta$ & As GH1374, but hxk1dac1nag1:SAT1/hxk1dac1nag1:hph & This study \\
\hline$n g t 1 \Delta / \Delta+N G T 1 p-N G T 1$ & As GH1374, but ngt1:FLP/ngt1:hph+NGT1p-NGT1:SAT1 & This study \\
\hline$h \times k 1 \Delta / \Delta+H X K 1 p-H X K 1$ & As GH1374, but $h x k 1: F L P / h x k 1: h p h+H X K 1 p-H X K 1: S A T 1$ & This study \\
\hline $\operatorname{dac} 1 \triangle / \triangle+D A C 1 p-D A C 1$ & As GH1374, but dac1:FLP/dac1:hph+DAC1p-DAC1:SAT1 & This study \\
\hline$n a g 1 \Delta / \Delta+N A G 1 p-N A G 1$ & As GH1374, but nag1:FLP/nag1:hph+NAG1p-NAG1:SAT1 & This study \\
\hline $\begin{array}{c}h x k 1 \Delta / \Delta \text { dac1 } 1 \Delta / \Delta \\
\text { nag1 } 1 \Delta / \Delta+H X K 1 p-H X K 1+D A C 1 p-D A C 1+N A G 1 p-N A G 1\end{array}$ & As GH1374, but $h x k 1: F L P / h x k 1: h p h+H X K 1 p-H X K 1: S A T 1$ & This study \\
\hline \multicolumn{3}{|l|}{ Plasmids } \\
\hline pCT3 & C. tropicalis expression vector; Amp & [39] \\
\hline pCT3-NGT1 & C. tropicalis NGT1 expression vector; Amp & This study \\
\hline pCT3-HХK1 & C. tropicalis HXK1 expression vector; Amp & This study \\
\hline pCT3-DAC1 & C. tropicalis DAC1 expression vector; Amp & This study \\
\hline pCT3-NAG1 & C. tropicalis NAG1 expression vector; Amp & This study \\
\hline pSF2A & Gene disruption vector containing a caSAT1 selection marker; Chlo & [52] \\
\hline pSF2A-NGT1KO & pSF2A carrying a NGT1 knockout cassette; Chlo & This study \\
\hline pSF2A-HXK1KO & pSF2A carrying a HXK knockout cassette; Chlo & This study \\
\hline pSF2A-DAC1KO & pSF2A carrying a $D A C 1$ knockout cassette; Chlo & This study \\
\hline pSF2A-NAG1KO & pSF2A carrying a NAG1 knockout cassette; Chlo & This study \\
\hline pSF2A-HXK1DAC1NAG1KO & pSF2A carrying a HXK1 DAC1 NAG1 knockout cassette; Chlo & This study \\
\hline pUC19T-hph-ca & The vector containing a caHPH selection marker; Amp & [39] \\
\hline pSF2A+NGT1 & Construct the $n g t 1 / n g t 1+N G T 1 p-N G T 1$ complemented strains & This study \\
\hline pSF2A+HXK1 & Construct the $h x k 1 / h x k 1+H X K 1 p-H X K 1$ complemented strains & This study \\
\hline pSF2A+DAC1 & Construct the $d a c 1 / d a c 1+D A C 1 p-D A C 1$ complemented strains & This study \\
\hline pSF2A+NAG1 & Construct the nag1/nag1+NAG1p-NAG1 complemented strains & This study \\
\hline pSF2A+HXK1+DAC1+NAG1 & Construct the $h x k 1 \Delta / \Delta$ dac1 $1 / \Delta$ nag1 $1 \Delta / \Delta+H X K 1 p-H X K 1+D A C 1 p-D A C 1+N A G 1 p-N A G 1$ complemented strains & This study \\
\hline
\end{tabular}


The pSF2A vector was used for deletion plasmid construction, using modified versions of a previously reported protocol [53]. NGT1, HXK1, DAC1, and NAG1 knockout plasmids were produced via the amplification of two flanking fragments (5'-UTR and 3'-UTR) from GH1374 genomic DNA for each gene, followed by digestion with the $\mathrm{ApaI} / \mathrm{XhoI}$ and $\mathrm{SacII} / \mathrm{SacI}$ restriction enzyme pairs prior to the insertion of the pSF2A plasmid, which contained a caSAT1 selection marker.

Table S1 details all primers used for plasmid generation in this study.

\subsection{Overexpression and Deletion Mutant Construction}

C. tropicalis overexpression mutants were generated based on a previous protocol [39]. Briefly, Ascl was used to linearize pCT3, pCT3-NGT1, pCT3-HXK1, pCT3-DAC1, and pCT3-NAG1, after which C. tropicalis (GH1374) was transformed using these plasmids, followed by selection on YPD agar plates supplemented with $100 \mathrm{~g} / \mathrm{L}$ nourseothricin. PCR was used to confirm proper insertion, and qRT-PCR was used to further confirm that the TDH3 promoter was able to promote NAG1, DAC1, HXK1, and NGT1 overexpression.

NGT1, HXK1, DAC1, and NAG1 were deleted via a slightly modified version of a previously reported protocol [54]. ApaI/SacI were used to linearize the pSF2A-NGT1KO, pSF2A-HXK1KO, pSF2A-DAC1KO, and pSF2A-NAG1KO constructs, after which they were used to transform C. tropicalis (GH1374). Transformed cells then underwent selection on YPD agar plates supplemented with $100 \mathrm{~g} / \mathrm{L}$ nourseothricin, and PCR was used to confirm proper insertion. To delete the second allele of these genes, a PCR fusion strategy was employed [20]. First, the flanking fragments for these individual genes were amplified from the GH1374 gDNA, as was the $c a H P H$ positive selection marker. Next, fusion PCR was conducted using these fragments as templates, and the strains in which the first allele of these genes had been deleted were then transformed with the PCR-amplified fragments, followed by selection on hygromycin B (100 g/L)-containing YPD agar plates. PCR was then used to confirm gene knockout. HXK1, DAC1, and NAG1 are close to one another on the same chromosome, and no other genes are present between these genes. As such, all three genes can be deleted in one step without accidentally deleting any other genes.

All primers used in the construction of these mutants are listed in Table S1.

\subsection{Construction of Complemented Strains}

To construct the NGT1/NGT1+NGT1p-NGT1 complemented strains, a strategy was used according to a previously reported protocol [5]. We firstly constructed plasmids pSF2A+NGT1, $\mathrm{pSF} 2 \mathrm{~A}+H X K 1, \mathrm{pSF} 2 \mathrm{~A}+D A C 1, \mathrm{pSF} 2 \mathrm{~A}+\mathrm{NAG1}$, and pSF2A+HXK1+DAC1+NAG1 for the transformation of corresponding mutant strains. Two fragments (one fragment containing the ORF, $5^{\prime}$-UTR and 3'-UTR of NGT1, HXK1, DAC1, or NAG1; the other fragment containing a corresponding 500bp 3'-UTR flanking fragment) were amplified from GH1374 genomic DNA for each gene, followed by digestion with the ApaI/XhoI and SacII/SacI restriction enzyme pairs prior to the insertion of the pSF2A plasmid, which contained a caSAT1 selection marker.

The $n g t 1 \Delta / \Delta, h x k 1 \Delta / \Delta$, dac $1 \Delta / \Delta$, and $n a g 1 \Delta / \Delta$ mutants and $h x k 1 \Delta / \Delta$ dac $1 \Delta / \Delta$ nag $1 \Delta / \Delta$ triple mutant were grown in YPM medium over a $48 \mathrm{~h}$ period for the FLP-mediated excision of the caSAT1/flipper cassette, generating the strains NGT1:FLP/NGT1:hph, HXK1:FLP/HXK1:hph, DAC1:FLP/DAC1:hph, NAG1:FLP/NAG1:hph, and HXK1DAC1NAG1:FLP/HXK1DAC1NAG1:hph.

$A p a I / S a c I$ were used to linearize the pSF2A+NGT1, pSF2A+HXK1, pSF2A+DAC1, pSF2A+NAG1, and pSF2A $+H X K 1+D A C 1+N A G 1$ constructs, after which they wre used to transform the strains NGT1:FLP/NGT1:hph, HXK1:FLP/HXK1:hph, DAC1:FLP/DAC1:hph, NAG1:FLP/NAG1:hph, and HXK1DAC1NAG1:FLP/HXK1DAC1NAG1:hph. Transformed cells then underwent selection on YPD agar plates supplemented with $100 \mathrm{~g} / \mathrm{L}$ nourseothricin, and PCR was used to confirm proper insertion. All primers used in the construction of these mutants are listed in Table S1. 


\subsection{C. tropicalis Transformation}

C. tropicalis strains were transformed by electroporation as described previously [51], with slight modifications. Cells from a single colony were initially inoculated in $2 \mathrm{~mL}$ fresh YPD medium at $30{ }^{\circ} \mathrm{C}$ for growth overnight, after which they were transferred into $100 \mathrm{~mL}$ fresh YPD medium and grown at $30^{\circ} \mathrm{C}$ to an optical density at $600 \mathrm{~nm}$ (OD600) of 1.7-1.9. Cells were then harvested and washed with $20 \mathrm{~mL}$ ice-cold distilled water. After cells were resuspended in $10 \mathrm{~mL}$ of $2 \times \mathrm{TE}$ buffer (10 mM Tris, $1 \mathrm{mM}$ EDTA, pH 8.0), $10 \mathrm{~mL}$ of $0.2 \mathrm{M}$ lithium acetate (Sigma Aldrich Chemie, Steinheim, Germany), $\mathrm{pH}$ 8.0, was added. The suspension was incubated in a rotary shaker at $150 \mathrm{rpm}$ for $60 \mathrm{~min}$ at $30^{\circ} \mathrm{C}$. A $500 \mu \mathrm{L}$ volume of $1 \mathrm{M}$ dithiothreitol was then added, and the cells were incubated for a further $30 \mathrm{~min}$ at $30^{\circ} \mathrm{C}$ with shaking. After the addition of $40 \mathrm{~mL}$ of water, the cells were centrifuged, washed sequentially in $30 \mathrm{~mL}$ of ice-cold water (thrice) and $10 \mathrm{~mL}$ of ice-cold $1 \mathrm{M}$ sorbitol, resuspended in $200 \mu \mathrm{L}$ of $1 \mathrm{M}$ sorbitol, and kept on ice. Next, $5 \mu \mathrm{L}(\sim 1 \mu \mathrm{g})$ of the linear DNA fragments were then mixed with $40 \mu \mathrm{L}$ of electrocompetent cells, and electroporation was carried out in an Equibio electroporator $(0.2 \mathrm{~cm}$ cuvette, $1.5 \mathrm{kV})$. After electroporation, the cells were washed in $1 \mathrm{~mL}$ of $1 \mathrm{M}$ sorbitol, resuspended in $2 \mathrm{~mL}$ YPD medium, and incubated in a rotary shaker at $200 \mathrm{rpm}$ for $2 \mathrm{~h}$ at $37^{\circ} \mathrm{C}$. The cells were plated on YPD plates containing $100 \mu \mathrm{g} / \mathrm{mL}$ of nourseothricin or hygromycin B, and then incubated at $37^{\circ} \mathrm{C}$ for 2 days.

\subsection{Assessment of Filamentous Growth}

Filamentous growth analysis was performed as described previously [39], with slight modifications. Five individual transformants for each gene were used for these assays. Cells from a single colony were first patched onto solid YPD medium plates. After culture at $25^{\circ} \mathrm{C}$ for 2 days, cells were harvested and washed with sterile distilled water $\left(\mathrm{ddH}_{2} \mathrm{O}\right)$ and replated onto solid Lee's plus glucose and Lee's plus GlcNAc medium plates. Approximately 50-70 cells were plated onto each $90 \mathrm{~mm}$ plate, after which they were incubated at $25^{\circ} \mathrm{C}$ or $37^{\circ} \mathrm{C}$ for filamentous growth analysis. Colony and cellular morphology were observed and photographed after incubation for 6 days.

\subsection{RNA Extraction}

RNA was isolated based on a slightly modified version of a previous protocol [55]. Initially, C. tropicalis cells isolated from a single cell were grown for 2 days on solid YPD medium plates, after which they were transferred to Lee's media agar plates supplemented with glucose or GlcNAc. After a three-day incubation at $25^{\circ} \mathrm{C}$, cells were washed thrice in cold distilled water, and then a GeneJET RNA Purification Kit was used, based on provided protocols, to extract cellular RNA. A NanoDrop 2000 instrument (Thermo Fisher Scientific, Waltham, MA, USA) was used to assess RNA concentrations, while gel electrophoresis was used to gauge RNA integrity.

\subsection{Quantitative Reverse Real-Time PCR (qRT-PCR)}

cDNA was generated using $1 \mu \mathrm{g}$ of total RNA from each sample $(1.0 \mu \mathrm{g})$ with a RevertAid first-strand cDNA synthesis kit (Thermo Fisher Scientific, Waltham, MA, USA), based on provided directions, after which cDNA samples were diluted in a $180 \mu \mathrm{L}$ total volume prior to use for qRT-PCR assays.

All qRT-PCR reactions were conducted in a $20 \mu \mathrm{L}$ volume containing $10 \mu \mathrm{L}$ SYBR Green Realtime PCR Master Mix (Toyobo Co., Ltd., Osaka, Japan), $2 \mu \mathrm{L}$ diluted cDNA, $0.8 \mu \mathrm{L}(10 \mu \mathrm{M})$ of each primer (Tianyi Huiyuan Company, Wuhan, China), and $6.4 \mu \mathrm{L}$ dd $_{2} \mathrm{O}$. Reactions were run on an ABI 7500 Real-Time PCR detection system (Applied Biosystems, Foster City, CA, USA) with the following parameters: $95^{\circ} \mathrm{C}$ for $60 \mathrm{~s} ; 40$ cycles of $95^{\circ} \mathrm{C}$ for $15 \mathrm{~s}, 58^{\circ} \mathrm{C}$ for $15 \mathrm{~s}$, and $72{ }^{\circ} \mathrm{C}$ for $45 \mathrm{~s}$; followed by a melting curve $\left(65^{\circ} \mathrm{C}\right.$ to $\left.95^{\circ} \mathrm{C}\right)$ to confirm product specificity. For normalization, C. tropicalis $A C T 1$ was used as a control. 
Supplementary Materials: The following are available online at http://www.mdpi.com/1422-0067/21/11/4036/s1, Table S1: Primers used in this study.

Author Contributions: Data curation, Q.Z. (Qiuyu Zhang), L.X., S.Y., Z.H. and Y.Y.; Formal analysis, Q.Z. (Qiuyu Zhang), L.X., S.Y., X.W. and L.W.; Funding acquisition, Y.Y.; Methodology, Q.Z. (Qiuyu Zhang), L.X., S.Y., X.W., L.W. and Z.H.; Writing—original draft, Q.Z. (Qiuyu Zhang), Q.Z. (Qinghua Zhou) and Y.Y.; Writing-review and editing, Q.Z. (Qiuyu Zhang), Q.Z. (Qinghua Zhou) and Y.Y. All authors have read and agreed to the published version of the manuscript.

Funding: This work was financially supported by the China Postdoctoral Science Foundation (2017M612439), the National Natural Science Foundation of China (31170078) the Natural Science Foundation of Hubei Province (2015CFA085), and the Fundamental Research Funds for HUST (2017KFYXJJ212).

Acknowledgments: We thank Guanghua Huang (Institute of Microbiology, Chinese Academy of Sciences) for generously providing plasmids pSF2A, pUC19T-hphca, and pCT3, and yeast strain GH1374.

Conflicts of Interest: The authors declare no conflict of interest.

\section{Abbreviations}

$\begin{array}{ll}\text { GlcNAc } & \text { N-acetylglucosamine } \\ \text { ACT1 } & \text { C. tropicalis actin gene } \\ \text { HXK1 } & \text { GlcNAc kinase gene } \\ \text { DAC1 } & \text { N-acetylglucosamine-6-phosphate deacetylase gene } \\ \text { NAG1 } & \text { Glucosamine-6-phosphate deaminase gene } \\ \text { NGT1 } & \text { GlcNAc-specific transporter gene }\end{array}$

\section{References}

1. Silva, S.; Negri, M.; Henriques, M.; Oliveira, R.; Williams, D.W.; Azeredo, J. Candida glabrata, Candida parapsilosis and Candida tropicalis: Biology, epidemiology, pathogenicity and antifungal resistance. FEMS Microbiol. Rev. 2012, 36, 288-305. [CrossRef]

2. Diba, K.; Makhdoomi, K.; Nasri, E.; Vaezi, A.; Javidnia, J.; Gharabagh, D.J.; Jazani, N.H.; Chavshin, A.R.; Badiee, P.; Badali, H.; et al. Emerging Candida species isolated from renal transplant recipients: Species distribution and susceptibility profiles. Microb. Pathog. 2018, 125, 240-245. [CrossRef]

3. Sudbery, P.; Gow, N.A.R.; Berman, J. The distinct morphogenic states of Candida albicans. Trends Microbiol. 2004, 12, 317-324. [CrossRef] [PubMed]

4. Whaley, S.G.; Berkow, E.L.; Rybak, J.M.; Nishimoto, A.T.; Barker, K.S.; Rogers, P.D. Azole Antifungal Resistance in Candida albicans and Emerging Non-albicans Candida Species. Front. Microbiol. 2017, 7, 1122. [CrossRef]

5. Guan, G.; Xie, J.; Tao, L.; Nobile, C.J.; Sun, Y.; Cao, C.; Tong, Y.; Huang, G. Bcr1 plays a central role in the regulation of opaque cell filamentation in Candida albicans. Mol. Microbiol. 2013, 89, 732-750. [CrossRef] [PubMed]

6. Cornely, O.A.; Bangard, C.; Jaspers, N.I. Hepatosplenic candidiasis. Clin. Liver Dis. 2015, 6, 47-50. [CrossRef]

7. $\mathrm{Su}, \mathrm{C}$; $\mathrm{Lu}, \mathrm{Y}$;; Liu, H. N-acetylglucosamine sensing by a GCN5-related $N$-acetyltransferase induces transcription via chromatin histone acetylation in fungi. Nat. Commun. 2016, 7, 12916. [CrossRef] [PubMed]

8. Drummond, R.; Lionakis, M.S. Organ-specific mechanisms linking innate and adaptive antifungal immunity. Semin. Cell Dev. Biol. 2019, 89, 78-90. [CrossRef]

9. Guinea, J. Global trends in the distribution of Candida species causing candidemia. Clin. Microbiol. Infect. 2014, 20, 5-10. [CrossRef]

10. Kothalawala, M.; Jayaweera, J.A.A.S.; Arunan, S.; Jayathilake, A. The emergence of non-albicans candidemia and evaluation of HiChrome Candida differential agar and VITEK2 YST®platform for differentiation of Candida bloodstream isolates in teaching hospital Kandy, Sri Lanka. BMC Microbiol. 2019, 19, 136. [CrossRef]

11. Krcmery, V.; Barnes, A. Non-albicans Candida spp. causing fungaemia: Pathogenicity and antifungal resistance. J. Hosp. Infect. 2002, 50, 243-260. [CrossRef] [PubMed]

12. Yang, Y.L.; Ho, Y.A.; Cheng, H.H.; Ho, M.; Lo, H.J. Susceptibilities of Candida species to amphotericin B and fluconazole: The emergence of fluconazole resistance in Candida tropicalis. Infect. Control Hosp. Epidemiol. 2004, 25, 60-64. [CrossRef] [PubMed] 
13. Kothavade, R.J.; Kura, M.M.; Valand, A.G.; Panthaki, M.H. Candida tropicalis: Its prevalence, pathogenicity and increasing resistance to fluconazole. J. Med. Microbiol. 2010, 59, 873-880. [CrossRef] [PubMed]

14. Lo, H.J.; Köhler, J.R.; DiDomenico, B.; Loebenberg, D.; Cacciapuoti, A.; Fink, G.R. Nonfilamentous C. albicans mutants are avirulent. Cell 1997, 90, 939-949. [CrossRef]

15. Biswas, S.; Van Dijck, P.; Datta, A. Environmental sensing and signal transduction pathways regulating morphopathogenic determinants of Candida albicans. Microbiol. Mol. Biol. Rev. 2007, 71, 348-376. [CrossRef]

16. Sudbery, P.E. Growth of Candida albicans hyphae. Nat. Rev. Microbiol. 2011, 9, 737-748. [CrossRef]

17. Witchley, J.N.; Penumetcha, P.; Abon, N.V.; Woolford, C.A.; Mitchell, A.P.; Noble, S.M. Candida albicans morphogenesis programs control the balance between gut commensalism and invasive infection. Cell Host Microbe 2019, 25, 432-443. [CrossRef]

18. Simonetti, N.; Strippoli, V.; Cassone, A. Yeast-mycelial conversion induced by N-acetyl-D-glucosamine in Candida albicans. Nature 1974, 250, 344-346. [CrossRef]

19. Klengel, T.; Liang, W.J.; Chaloupka, J.; Ruoff, C.; Schröppel, K.; Naglik, J.R.; Eckert, S.E.; Mogensen, E.G.; Haynes, K.; Tuite, M.F.; et al. Fungal adenylyl cyclase integrates $\mathrm{CO}_{2}$ sensing with cAMP signaling and virulence. Curr. Biol. 2005, 15, 2021-2026. [CrossRef]

20. Tao, L.; Zhang, Y.; Fan, S.; Nobile, C.J.; Guan, G.; Huang, G. Integration of the tricarboxylic acid (TCA) cycle with cAMP signaling and $\mathrm{Sfl} 2$ pathways in the regulation of $\mathrm{CO}_{2}$ sensing and hyphal development in Candida albicans. PLoS Genet. 2017, 13, e1006949. [CrossRef]

21. Butler, G.; Rasmussen, M.D.; Lin, M.F.; Santos, M.A.S.; Sakthikumar, S.; Munro, C.; Rheinbay, E.; Grabherr, M.; Forche, A.; Reedy, J.L.; et al. Evolution of pathogenicity and sexual reproduction in eight Candida genomes. Nature 2009, 459, 657-662. [CrossRef] [PubMed]

22. Santos, M.A.S.; Gomes, A.C.; Santos, M.C.; Carreto, L.C.; Moura, G.R. The genetic code of the fungal CTG clade. Comptes Rendus Biol. 2011, 334, 607-611. [CrossRef] [PubMed]

23. Zuza-Alves, D.L.; Silva-Rocha, W.P.; Chaves, G.M. An update on Candida tropicalis based on basic and clinical approaches. Front. Microbiol. 2017, 8, 1927. [CrossRef]

24. Lin, C.J.; Chen, Y.L. Conserved and divergent functions of the cAMP/PKA signaling pathway in Candida albicans and Candida tropicalis. J. Fungi 2018, 4, 68. [CrossRef] [PubMed]

25. Ferreira, C.; Gonçalves, B.; Oliveira, H.; Boas, D.V.; Henriques, M.; Azeredo, J.; Silva, S. Candida tropicalis biofilm and human epithelium invasion is highly influenced by environmental pH. Pathog. Dis. 2016, 74, 8. [CrossRef]

26. Mayer, F.; Wilson, D.; Hube, B. Candida albicans pathogenicity mechanisms. Virulence 2013, 4, 119-128. [CrossRef]

27. Gow, N.A.R.; Van De Veerdonk, F.L.; Brown, A.J.; Netea, M.G. Candida albicans morphogenesis and host defence: Discriminating invasion from colonization. Nat. Rev. Microbiol. 2011, 10, 112-122. [CrossRef]

28. Odds, F.C. Molecular phylogenetics and epidemiology of Candida albicans. Futur. Microbiol. 2010, 5, 67-79. [CrossRef]

29. Burgain, A.; Pic, É.; Markey, L.; Tebbji, F.; Kumamoto, C.A.; Sellam, A. A novel genetic circuitry governing hypoxic metabolic flexibility, commensalism and virulence in the fungal pathogen Candida albicans. PLoS Pathog. 2019, 15, e1007823. [CrossRef]

30. Kutty, S.N.; Philip, R. Marine yeasts-A review. Yeast 2008, 25, 465-483. [CrossRef]

31. Yan, K.; Zhang, Y.; Zhenming, C. Distribution and diversity of Candida tropicalis strains in different marine environments. J. Ocean Univ. China 2010, 9, 139-144. [CrossRef]

32. Ogawa, M.; Okajima, T. Structure and function of extracellular O-GlcNAc. Curr. Opin. Struct. Biol. 2019, 56, 72-77. [CrossRef]

33. Du, H.; Guan, G.; Li, X.; Gulati, M.; Tao, L.; Cao, C.; Johnson, A.D.; Nobile, C.J.; Huang, G. $\mathrm{N}$-acetylglucosamine-induced cell death in Candida albicans and its implications for adaptive mechanisms of nutrient sensing in yeasts. MBio 2015, 6, e01376-15. [CrossRef]

34. Osada, M.; Kobayashi, H.; Miyazawa, T.; Suenaga, S.; Ogata, M. Non-catalytic conversion of chitin into Chromogen I in high-temperature water. Int. J. Biol. Macromol. 2019, 136, 994-999. [CrossRef]

35. Huang, G.; Yi, S.; Sahni, N.; Daniels, K.J.; Srikantha, T.; Soll, D.R. N-acetylglucosamine induces white to opaque switching, a mating prerequisite in Candida albicans. PLoS Pathog. 2010, 6, e1000806. [CrossRef] 
36. Gilmore, S.A.; Naseem, S.; Konopka, J.B.; Sil, A. N-acetylglucosamine (GlcNAc) triggers a rapid, temperatureresponsive morphogenetic program in thermally dimorphic fungi. PLoS Genet. 2013, 9, e1003799. [CrossRef] [PubMed]

37. Torres-Guzman, J.C.; Dominguez, A. HOY1, a homeo gene required for hyphal formation in Yarrowia lipolytica. Mol. Cell Biol. 1997, 17, 6283-6293. [CrossRef] [PubMed]

38. Perez-Campo, F.M.; Domínguez, Á. Factors affecting the morphogenetic switch in Yarrowia lipolytica. Curr. Microbiol. 2001, 43, 429-433. [CrossRef]

39. Zhang, Q.; Tao, L.; Guan, G.; Yue, H.; Liang, W.; Cao, C.; Dai, Y.; Huang, G. Regulation of filamentation in the human fungal pathogen Candida tropicalis. Mol. Microbiol. 2015, 99, 528-545. [CrossRef] [PubMed]

40. Alvarez, F.J.; Konopka, J.B. Identification of an $N$-acetylglucosamine transporter that mediates hyphal induction in Candida albicans. Mol. Biol. Cell 2007, 18, 965-975. [CrossRef]

41. Huang, G. Regulation of phenotypic transitions in the fungal pathogen Candida albicans. Virulence 2012, 3, 251-261. [CrossRef] [PubMed]

42. Kumar, M.J.; Jamaluddin, S.; Natarajan, K.; Kaur, D.; Datta, A. The inducible N-acetylglucosamine catabolic pathway gene cluster in Candida albicans: Discrete $N$-acetylglucosamine-inducible factors interact at the promoter of NAG1. Proc. Natl. Acad. Sci. USA 2000, 97, 14218-14223. [CrossRef] [PubMed]

43. Kappel, L.; Gaderer, R.; Flipphi, M.; Seidl-Seiboth, V. The N-acetylglucosamine catabolic gene cluster in Trichoderma reeseiis controlled by the Ndt80-like transcription factor RON1. Mol. Microbiol. 2015, 99, 640-657. [CrossRef] [PubMed]

44. Naseem, S.; Gunasekera, A.; Araya, E.; Konopka, J.B. N-Acetylglucosamine (GlcNAc) induction of hyphal morphogenesis and transcriptional responses in Candida albicans are not dependent on its metabolism. J. Biol. Chem. 2011, 286, 28671-28680. [CrossRef] [PubMed]

45. Carlisle, P.L.; Banerjee, M.; Lazzell, A.; Monteagudo, C.; López-Ribot, J.L.; Kadosh, D. Expression levels of a filament-specific transcriptional regulator are sufficient to determine Candida albicans morphology and virulence. Proc. Natl. Acad. Sci. USA 2009, 106, 599-604. [CrossRef]

46. Thompson, D.S.; Carlisle, P.L.; Kadosh, D. Coevolution of morphology and virulence in Candida Species. Eukaryot. Cell 2011, 10, 1173-1182. [CrossRef]

47. Naseem, S.; Konopka, J.B. N-acetylglucosamine regulates virulence properties in microbial pathogens. PLoS Pathog. 2015, 11, e1004947. [CrossRef]

48. Chowdhary, A.; Hagen, F.; Sharma, C.; Al-Hatmi, A.; Giuffrè, L.; Giosa, D.; Fan, S.; Badali, H.; Felice, M.R.; De Hoog, S.; et al. Whole genome-based amplified fragment length polymorphism analysis reveals genetic diversity in Candida africana. Front. Microbiol. 2017, 8, 167. [CrossRef]

49. Pérez-Martín, J.; Uría, J.A.; Johnson, A.D. Phenotypic switching in Candida albicans is controlled by a SIR2 gene. EMBO J. 1999, 18, 2580-2592. [CrossRef]

50. Rao, K.H.; Ghosh, S.; Natarajan, K.; Datta, A. N-Acetylglucosamine Kinase, HXK1 Is Involved in morphogenetic transition and metabolic gene expression in Candida albicans. PLoS ONE 2013, 8, e53638. [CrossRef]

51. Cao, C.; Guan, G.; Du, H.; Tao, L.; Huang, G. Role of the $N$-acetylglucosamine kinase (Hxk1) in the regulation of white-gray-opaque tristable phenotypic transitions in C. albicans. Fungal Genet. Biol. 2016, 92, $26-32$. [CrossRef]

52. Reuß, O.; Vik, A.; Kolter, R.; Morschhäuser, J. The SAT1 flipper, an optimized tool for gene disruption in Candida albicans. Gene 2004, 341, 119-127. [CrossRef] [PubMed]

53. Xie, J.; Tao, L.; Nobile, C.J.; Tong, Y.; Guan, G.; Sun, Y.; Cao, C.; Hernday, A.D.; Johnson, A.D.; Zhang, L.; et al. White-opaque switching in natural MTLa/ $\alpha$ Isolates of Candida albicans: Evolutionary implications for roles in host adaptation, pathogenesis, and sex. PLoS Biol. 2013, 11, e1001525. [CrossRef] [PubMed] 
54. Porman, A.M.; Hirakawa, M.P.; Jones, S.K.; Wang, N.; Bennett, R.J. MTL-independent phenotypic switching in Candida tropicalis and a dual role for Wor1 in regulating switching and filamentation. PLoS Genet. 2013, 9, e1003369. [CrossRef] [PubMed]

55. Tao, L.; Du, H.; Guan, G.; Dai, Y.; Nobile, C.J.; Liang, W.; Cao, C.; Zhang, Q.; Zhong, J.; Huang, G. Discovery of a "white-gray-opaque" tristable phenotypic switching system in Candida albicans: Roles of non-genetic diversity in host adaptation. PLoS Biol. 2014, 12, e1001830. [CrossRef] [PubMed]

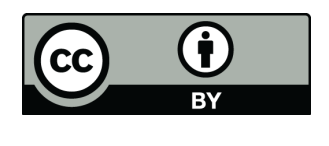

(C) 2020 by the authors. Licensee MDPI, Basel, Switzerland. This article is an open access article distributed under the terms and conditions of the Creative Commons Attribution (CC BY) license (http://creativecommons.org/licenses/by/4.0/). 